* Advogado. Mestre em saúde e tecnologia no espaco hospitalar pela UNIRIO, membro da Comissão Permanente de Licitação do HUGG - UNIRIO

E-mail: fabiounirio@hotmail. com

**Ph.D pela Universidade Federal do Estado do Rio de Janeiro. Departamento de Pós-Graduação - Escola de Enfermagem Alfredo Pinto da Unirio.

E-mail: wilmachado@uol.com. br

***Doutora pela Universidade Federal do Estado do Rio de Janeiro. Profa. Doutora da Universidade Federal do Estado do Rio de Janeiro. Departamento de Pós-Graduação - Escola de Enfermagem Alfredo Pinto da Unirio.

E-mail: nebia43@gmail.com

\section{Visão JURídico-Administrativa nas AQUisições por Pregão: Busca de Qualidade em Hospital UNIVERSITÁRIO do Rio DE JANEIRO}

\author{
Legal-Administrative View On The Acquisitions Per \\ Floor: Quality Search at University Hospital Of Rio \\ DE JANEIRO
}

\section{Fabio Gonçalves Vilas Filho* Wiliam Cesar Alves Machado** Nébia Maria Almeida Figueiredo***}

Como citar: VILAS FILHO, Fabio Gonçalves; MACHADO, Wiliam Cesar Alves; FIGUEIREDO, Nébia Maria Almeida. Visão jurídico-administrativa nas aquisições por pregão: busca de qualidade em hospital universitário do rio de janeiro. Revista do Direito Público, Londrina, v. 14, n. 2, p. 10-27, ago. 2019. DOI: 10.5433/24157-108104-1.2019v14n2p. 10. ISSN: 1980-511X

Resumo: O presente estudo buscou avaliar se as aquisições oriundas dos processos de compras de materiais hospitalares através do pregão eletrônico, em hospital universitário do Rio de Janeiro, atende ao princípio de segurança para realização dos procedimentos terapêuticos primordiais na recuperação dos pacientes. Constatou-se a necessidade de se realizar análise prévia dos insumos, por uma comissão de pré-qualificação, que apesar de não haver previsão na legislação que regula o pregão, a medida se justifica, diante da morosidade dos testes das amostras quando estas ocorrem no curso do pregão, bem como diante dos inúmeros pareceres negativos que corroboram no sentido de que a baixa qualidade dos insumos oferecidos pelos licitantes pode trazer prejuízos para a administração nos aspectos financeiros, sobretudo no agravamento do quadro clínico dos pacientes e estresse das equipes de saúde envolvidas no procedimento.

Palavras-Chaves: Pregão eletrônico. Controle de qualidade. Segurança do paciente. Gestão hospitalar.

Abstract: This study sought to evaluate if acquisitions of materials from hospital purchases from the use of the electronic "pregão", in a university hospital in Rio de Janeiro, respects the principle of safety - as it is fundamental in accomplishing primary therapeutic procedures in patient recovery. This paper confirmed the need to carry out a preliminary analysis of inputs by a pre-qualification commission, which, despite the fact that there is no provision 
in Brazilian legislation regulating this session, is justified given the lengthy testing of the samples, as well as the numerous negative opinions that corroborate the low quality of the inputs offered by bidders, which can concur financial losses for the public administration, and it can, even worse, aggravate patients' wellbeing.

Key Words: Electronic Research, Quality Control, Patient Safety, Hospital Management. 


\section{INTRODUÇÃO}

Os processos de compras, na área da saúde, são procedimentos muito complexos, onde atuam profissionais da saúde e administrativo e, sobretudo, são os que geram maior custo para administração hospitalar. Além disso, devido ao surgimento de novos insumos e técnicas para o ambiente hospitalar, os sujeitos envolvidos diretamente com a aquisição de materiais precisam manter-se constantemente atualizados.

Vale frisar que, tanto as instituições particulares quanto as públicas buscam comprar pelo menor preço e adquirir produtos com o máximo de qualidade, contudo em razão do principio da legalidade a administração pública deverá seguir somente aquilo que a lei autoriza, ou seja, os órgãos governamentais para adquirir bens e serviços necessitarão realizar processo licitatório, salvo os casos expressos no ordenamento jurídico que trata do assunto e, neste cenário, os hospitais públicos universitários para atingir seus objetivos de prestar um atendimento com segurança e qualidade aos seus usuários (pacientes e profissionais de saúde), estão inseridos.

Por outro lado, as instituições privadas podem fazer tudo àquilo que não é proibido por lei, logo estão livres para comprar os insumos para saúde dos fornecedores e das marcas que melhor lhe prouver.

Segundo Di Pietro (2010), licitação é o procedimento pelo qual a administração pública, abre aos licitantes interessados a possibilidade de ofertarem suas propostas, nas condições estabelecidas no instrumento convocatório, a fim de selecionar a mais conveniente para a efetivação do contrato.

No Brasil a Lei $n^{\circ}$ 8.666/93, estabelece cinco modalidades de licitação, quais sejam: concorrência, tomada de preços, convite, concurso e leilão. Ocorre que estas tradicionais modalidades, devido aos seus procedimentos extremamente burocráticos, há muito tempo não estavam atendendo às necessidades de se adquirir os insumos com a celeridade e transparência desejada.

Desse modo, o Governo Federal instituiu através da Lei $\mathrm{n}^{0} 10.520 / 2002$, uma nova modalidade denominada, pregão, em função da necessidade de maior celeridade na efetivação dos contratos pela Administração Pública. O pregão possui duas formas, o presencial e o eletrônico, este último regulamentado pelo Decreto $\mathrm{n}^{\circ} 5.450 / 2005$.

Ressalta-se que o referido Decreto estabelece a exigência de utilização do pregão, preferencialmente na forma eletrônica, para entes públicos nas contratações de bens e serviços comuns evidentemente pela maior transparência, já que o procedimento ocorre via Web, podendo ser fiscalizado em tempo real.

Para Justen Filho (2009), o pregão é um procedimento de licitação destinado a selecionar a proposta mais vantajosa para o ente público na contratação de produtos e serviços, cujo critério de julgamento é o menor preço, caracterizado pela fase competitiva inicial, em que os interessados dispõem do ônus de formular ofertas e lances sucessivos e posteriormente à verificação dos requisitos de habilitação.

Contudo, apesar da maior celeridade, transparência e da economia decorrentes dos 
procedimentos existentes no pregão eletrônico, se observou no presente estudo que as aquisições oriundas não atendem ao requisito de qualidade, trazendo desperdícios a médio e longo prazo conforme será demonstrado com análise de 136 pregões realizados em um grande hospital universitário do Rio de Janeiro,

Diante do cenário, apesar de não haver previsão na legislação que instituiu a modalidade de licitação pregão, constatou-se a necessidade de se instituir uma comissão de pré-qualificação, já que há morosidade dos testes das amostras quando estes ocorrem no curso do procedimento e os inúmeros pareceres negativos corroboram no sentido de que a baixa qualidade dos insumos oferecidos pelos licitantes pode trazer prejuízos para a administração nos aspectos financeiros, sobretudo no agravamento do quadro clínico dos pacientes e estresse das equipes de saúde envolvidas no procedimento.

\section{MÉTODO}

Trata-se de estudo observacional descritivo de abordagem quantitativa. O cenário do estudo compõe-se do fluxo da Comissão de Licitação do Hospital Universitário Gaffrée e Guinle. A amostra foi extraída da documentação física de processos de compras na modalidade pregão eletrônicos desde a abertura e publicação dos editais até a fase de homologação, realizados no período de 2010 a 2015.

Observou-se 136 processos de licitação, dos quais 40 foram solicitadas amostra dos insumos e 96 sem amostra. Para a análise, criou-se instrumento em forma de planilha no software Excel, na qual se registraram as observações com informações separadas nas seguintes colunas: valor estimado da compra e valor homologado; data de início e fim; número de itens total, itens cancelados e desertos; número de solicitações de amostras; número de pareceres negativos e positivos.

A partir dos elementos colhidos, foram instituídas seis colunas correspondentes aos índices e razões. Estes foram criados por meio do software Excel e foram manipuladas pelo software R para criação das tabelas e gráficos da análise quantitativa e a realização de testes de hipótese.

- Índice de economia foi calculado por meio da diferença entre o valor estimado e o de compra, dividido pelo valor estimado de compra.

- A variável de tempo está representada em dias úteis.

- As razões de deserção e cancelamento foram expressas pelo número de cancelamentos divido pelo número total de itens do processo.

- As razões de pareceres positivos e negativos são representadas pela razão entre o número de pareceres positivos e negativos obtidos pelo número de amostras pedidas para cada pregão. Essas razões são relativas ao universo com amostra (com 40 observações).

Posteriormente, o banco de dados foi carregado no software $\mathrm{R}$, com a utilização da plataforma Rcmdr (Rcommander). Os resumos numéricos, gráficos e testes estatísticos foram convertidos integralmente em texto ou imagem para a confecção de relatório. Ressalta-se que o nível de significância adotado em todos os testes foi de $5 \%$. Para testar a normalidade foi 
utilizado o teste de Shapiro-Wilk e como a suposição de normalidade não foi satisfeita, optou-se por testes não paramétricos, a saber: Kruskal-Wallis e Wilcoxon.

Com os resultados obtidos foi possível discutir diante das Normas vigentes no país, doutrinas, artigos e dissertações que se relacionam com a temática do estudo, ou seja, que abordam a qualidade dos materiais terapêuticos para aferir quais são as medidas administrativas a serem adotadas para melhoria da qualidade das compras desses insumos e com a experiência contribuir para ampliar a eficiência.

Os resultados se guiaram pela interpretação e classificação dos níveis de evidências encontrados. A análise foi elaborada a partir da qualidade dos materiais terapêuticos adquiridos e de quais medidas administrativas podem ser adotadas para melhoria da qualidade das compras desses materiais.

\section{AS COMPRAS DE INSUMOS TERAPÊUTICOS REALIZADAS EM HOSPITAL UNIVERSITÁRIO}

\subsection{Resultados E Discussões}

\subsubsection{Seção economia}

Na Tabela 1 encontram-se os valores estimados, os valores finais das compras e economia (diferença entre o valor estimado e o valor final), estes resultados foram estratificados pelos pregões com e sem amostra.

Tabela 1 - Valores estimados e homologados em pregões realizados em hospital universitário (Rio de Janeiro/RJ/2015).

\begin{tabular}{c|c|c|c}
\hline Pregões & Com amostras (40) & Sem amostras (96) & Todos (136) \\
\hline Valor Estimado & $\mathrm{R} \$ 39.392 .499,85$ & $\mathrm{R} \$ 82.268 .084,51$ & $\mathrm{R} \$ 121.660 .584,36$ \\
\hline Valor da Compra & $\mathrm{R} \$ 24.033 .473,32$ & $\mathrm{R} \$ 46.034 .033,31$ & $\mathrm{R} \$ 70.067 .506,63$ \\
\hline Economia & $\mathrm{R} \$ 15.359 .026,53$ & $\mathrm{R} \$ 36.234 .051,20$ & $\mathrm{R} \$ 51.593 .077,73$ \\
\hline
\end{tabular}

Fonte: Elaboração própria.

Vale destacar que os valores estimados são obtidos por meio da média de três orçamentos pesquisados junto ao mercado de fornecedores e pelas atas de pregões homologados disponíveis no Portal de Compras do Governo Federal. Os preços finais de compra e homologados são obtidos após a fase de lance, haja vista que o pregão se assemelha ao leilão. No entanto, ao inverso, ou seja, quem ofertar o menor lance será o vencedor, registrando que, mesmo após os lances, ainda são possíveis negociações para melhor preço final. 
O pregão eletrônico apresenta vantagens na competição em relação às demais modalidades licitatórias, uma vez que racionaliza os procedimentos, há redução de preços e, sobretudo, transparência nos procedimentos, pois são via internet e, por esse motivo podemos constatar na tabela 1 a economia alcançada em todas as estratificações.

De acordo com Croom (2000), o uso da tecnologia traz maior celeridade na aquisição e minimiza os custos, já que o uso frequente da web para as transações comerciais é considerado como uma revolução, pois, trouxe benefícios na redução dos custos administrativos, incluindo o controle sobre as despesas.

Destacam Freitas e Maldonado (2013), ainda a maior transparência, uma vez que as transações podem ser acompanhadas em tempo real. A possibilidade de participação na licitação à distância - as empresas de qualquer localidade do Brasil podem participar da sessão pública por meio da internet - aumenta a transparência e dá maior publicidade aos atos, trazendo a possibilidade de qualquer cidadão acompanhar também pela internet o desenvolvimento das sessões públicas e os atos praticados por todos os envolvidos no pregão.

Justen Filho (2009) aponta ainda como aspecto, positivo para a redução dos preços no pregão é o fato de a fase de lances serem posterior à apresentação das propostas, assim os fornecedores podem elevar a vantagem de sua proposta.

Tabela 2 - Medidas descritivas para índice de economia dos pregões realizados no Hospital Universitário (Rio de Janeiro/RJ/2015).

\begin{tabular}{c|c|c|c|c}
\hline & Média & Desvio padrão & Mediana & Número \\
\hline Total & 0.352 & 0.411 & 0.38 & 136 \\
\hline Com amostra & 0.457 & 0.28 & 0.485 & 40 \\
\hline Sem amostra & 0.308 & 0.449 & 0.32 & 96 \\
\hline
\end{tabular}

Fonte: Elaboração própria.

A tabela 2 representa as medidas descritivas para o índice economia entre as licitações "com amostra" e "sem amostra", respectivamente. Como se pode observar acima, as licitações do tipo "com amostra" apresentam média e mediana com índices de economia superiores.

Existe diferença estatisticamente significativa $(\mathrm{p}=0.018)$ de acordo com o teste de Wilcoxon, entre as medianas do índice de economia entre os dois tipos de licitação. Sendo menor o índice de economia no tipo "sem amostra" que "com amostra".

Certamente, essa economia nos pregões com amostras, ocorrerá, já que os produtos de qualidade inferior foram rejeitados, evitando desperdícios, uma vez que materiais de baixa qualidade são mais utilizados, ocasionando repetições nos procedimentos.

Encontra-se em Garcia e colaboradores (2012), trechos de entrevistas nesse sentido: “Às vezes o produto é mais barato, mas acaba sendo necessário utilizar três unidades, tornando relativamente mais caro". Tal constatação nos leva a crer, que a aparente economia do menor preço poderá gerar também perda de tempo, esforços desnecessários e, ainda pode colocar em 
risco a segurança do paciente e profissional de saúde.

Por isso, é preciso se ter em mente que a avaliação não deve se restringir somente ao critério menor preço, mas é necessário mensurar qual é o menor preço dentro da melhor qualidade tendo em vista que essa modalidade de licitação privilegia o menor preço e conduz à obtenção de preços mais reduzidos.

Por outro lado, o pregão versa sobre "objeto comum", o que faz com que todos os produtos disponíveis no mercado sejam oferecidos para a administração. Daí segue o risco de se selecionar uma proposta de menor valor com a qualidade imprestável. A adoção desse procedimento não significa que a entidade pública seja constrangida a comprar produtos de qualidade inadequada apenas pelo fato de buscar o menor preço (JUSTEN FILHO, 2009).

Tabela 3 - Índice de economia através dos anos de pregões realizados no período de 2010 a 2015 em hospital universitário (Rio de Janeiro/RJ/2015).

\begin{tabular}{c|c|c|c|c}
\hline Ano & Média & Desvio padrão & Mediana & Número total \\
\hline 2010 & 0.42 & 0.24 & 0.43 & 20 \\
\hline 2011 & 0.45 & 0.29 & 0.47 & 25 \\
\hline 2012 & 0.41 & 0.29 & 0.45 & 20 \\
\hline 2013 & 0.31 & 0.26 & 0.36 & 26 \\
\hline 2014 & 0.19 & 0.75 & 0.3 & 23 \\
\hline 2015 & 0.32 & 0.35 & 0.31 & 22 \\
\hline
\end{tabular}

Fonte: Elaboração própria.

A tabela 3 e o respectivo gráfico 1, destaca a economia referente aos pregões realizados no período de 2010 a 2015. Nesses casos, o número de processos realizados no decorrer de cada ano, bem como o tipo de objeto a ser licitado determinará essa variável, podendo ocorrer mais ou menos pregões de acordo com a demanda do hospital.

Não foi encontrada diferença estatisticamente significativa entre os anos ( $p=0,417)$. Em geral, apesar de não haver significância a 5\%, o índice de economia variou com a passagem do tempo e para representar essa variância usou-se a mediana para realização de cálculo de crescimento.

De 2010 para 2011, o índice cresceu 8,51\%. No período de 2011 a 2012, o índice caiu 4,25\%; de 2012 a 2013, o índice caiu 20\%, a maior queda relatada. De 2013 a 2014, o índice voltou a cair em 16\%; no ano de 2014, foram obtidos os menores índices e as mais variáveis. Ou seja, poucas observações foram responsáveis pela queda abrupta do índice, ao contrário do ano anterior, que apresenta o segundo pior ano em relação à economia.

Porém, essa queda foi mais distribuída entre as licitações observadas. Em 2015, o índice de economia cresceu 3,22\% em relação ao ano anterior, apresentando, ainda que discreto, um crescimento pela primeira vez desde 2011. O Gráfico 1 representa o boxplot para o índice de economia através dos anos. Vejamos:

Gráfico 1 - Boxplot: Índice de economia através dos anos de pregões realizados no período de 
2010 a 2015 em hospital universitário (Rio de Janeiro/RJ/2015).

Fonte: Elaboração própria.

É interessante notar no gráfico 1, o parecer 111, para pregão realizado em 2014. Neste, particularmente, detectou-se um fato atípico: para essa licitação, não houve economia em relação ao valor estimado e publicado ( $\mathrm{R} \$ 1.042 .328,33$ ), já que o valor de compra foi de $\mathrm{R} \$$ 4.252.163,50; contudo, constatou-se que a planilha de preços estimada estava desatualizada, e que em licitação similar em outros órgãos o valor final correspondia à realidade do mercado naquele momento, por esse motivo homologou-se o pregão.

\subsubsection{Seção - Tempo em Dias Úteis}

A tabela 4 representa, respectivamente, as medidas descritivas das licitações "com amostra" e "sem amostra". Como se pode observar, a mediana de tempo em dias úteis nos pregões com amostras é superior, portanto, há morosidade.

Tabela 4 - Medidas descritivas para a variável tempo em dias úteis de pregões realizados com amostras e sem amostras em hospital universitário (Rio de Janeiro/RJ/2015).

\begin{tabular}{c|c|c|c|c}
\hline & Média & Desvio padrão & Mediana & Número total \\
\hline Total & 28.75 & 31.917 & 17.5 & 136 \\
\hline Com Amostra & 43.000 & 24.248 & 41.0 & 40 \\
\hline Sem amostra & 22.812 & 32.941 & 12.5 & 96 \\
\hline
\end{tabular}

Fonte: Elaboração própria.

A diferença entre a mediana do tempo nos dois tipos de licitação é estatisticamente significativa, sendo maior no tipo "com amostra", segundo o teste de Kruskal-Wallis. $(\mathrm{p}<0$, 001). Essa diferença pode ser observada no Gráfico abaixo:

Gráfico 2 - Boxplot para o fator tempo em dias úteis de pregões realizados em hospital universitário (Rio de Janeiro/RJ/2015).

Fonte: Elaboração própria.

Relevante destacar na tabela 4 e respectivo gráfico 2 que a celeridade é fundamental na modalidade de licitação pregão, bem como os procedimentos processuais simplificados, sendo esses alguns dos principais motivos para se instituir o pregão. Entretanto, vislumbramos nos dados estatísticos apresentados que, quando há análise de amostras no curso do certame, o processo é moroso, pois desde o início da sessão até a homologação o prazo é de 43 dias úteis.

Tal cenário, não contribui para a eficiência, sobretudo por haver pacientes internados no hospital que dependem desses materiais. O Portal de Compras Governamentais menciona que 
todo o procedimento do pregão seja de 17 dias (COMPRASNET, 2005).

Na mesma direção aponta estudo realizado por Faria e colaboradores (2008), onde os pesquisadores constataram um tempo médio total de 15 dias entre a abertura da sessão e a homologação do pregão. O tempo é fator fundamental na aquisição de materiais médicos hospitalares, visto que nas instituições de saúde há dezenas de pacientes que dependem desses materiais.

Destaca-se, como forma de maior rapidez ao certame, a sua inversão de fases. Nas demais modalidades, os fornecedores são habilitados em primeiro plano para, posteriormente, serem classificados.

Na prática, essa inversão funciona da seguinte forma: imagine que, em um universo de 100 fornecedores, os envelopes contendo os documentos de habilitação de todos sejam analisados e, somente após o término, sejam analisados os invólucros com as propostas de cada licitante. Ou seja, primeiro se habilita e depois se classifica.

Já no pregão eletrônico a fase é invertida, pois, primeiro o sistema classifica automaticamente o menor valor e, somente do detentor deste é que se faz a análise da documentação de habilitação. Isso sem dúvida traz maior rapidez ao procedimento. Sendo a inversão de fases um dos pontos relevantes para o sucesso.

Faria e colaboradores (2011), destacam as duas características principais: 1) Inversão das fases de habilitação e julgamento e 2) Possibilidade de renovação de lances por todos ou alguns dos licitantes, até se chegar à proposta mais vantajosa.

\subsubsection{Seção - Cancelamentos e Deserções}

A Tabela 5 representa, respectivamente, valores descritivos da variável cancelamento e da variável deserção das licitações "com amostra" e "sem amostra". Embora o processo licitatório com amostra, aparentemente, possa gerar mais cancelamentos e deserções, essa diferença não é estatisticamente significativa para a variável cancelamento $(\mathrm{p}=0,077)$ e nem para a variável deserção $(p=0,058)$.

Tabela 5 - Medidas descritivas para a variável cancelamentos e deserções dos pregões realizados em hospital universitário (Rio de Janeiro/RJ/2015).

\begin{tabular}{c|c|c|c|c|c}
\hline & & Média & Desvio padrão & Mediana & $\begin{array}{c}\text { Número } \\
\text { total }\end{array}$ \\
\hline \multirow{3}{*}{ Cancelamentos } & Com Amostra & 0.127 & 0.208 & 0.05 & 40 \\
\cline { 2 - 6 } & Sem Amostra & 0.058 & 0.185 & 0.00 & 96 \\
\hline
\end{tabular}


FABIO GONÇALVES VILAS FILHO E WILIAM CESAR ALVES MACHADO E NÉBIA MARIA ALMEIDA FIGUEIREDO

\begin{tabular}{c|c|c|c|c|c}
\hline & & Média & Desvio padrão & Mediana & $\begin{array}{c}\text { Número } \\
\text { total }\end{array}$ \\
\hline \multirow{3}{*}{ Deserções } & Com Amostra & 0.045 & 0.135 & 0 & 40 \\
\cline { 2 - 6 } & Sem Amostra & 0.017 & 0.048 & 0 & 96 \\
\hline
\end{tabular}

Fonte: Elaboração própria.

O valor resultante do teste de Kruskal-Wallis para o índice de deserção é considerado limítrofe, portanto, a decisão de rejeitar ou aceitar a significância da diferença entre os grupos não deve ser baseada apenas nesse teste. Deve-se também ser levado em conta o referencial teórico para explicar, de fato, essa relação.

O processo licitatório com amostra, aparentemente, tende a gerar mais cancelamentos e deserções. No que se refere ao cancelamento, isso se justifica pelo fato de que quanto mais se exige qualidade, os produtos que não atenderem a esse padrão serão recusados, fazendo com que se aproximem do valor máximo que a administração se dispõe a pagar, o que é expressamente vedado pelos editais.

Para a deserção, quanto mais especificado o item no intuito de se adquirirem insumos que trazem segurança para os pacientes e aos profissionais, mais pode haver desinteresse dos maus fornecedores em concorrer, ou seja, participar do certame.

Segundo Kurcgant P. e colaboradores (1991), a especificação técnica é a descrição minuciosa das características do produto desejado para que se possibilite a compra do mesmo. Portanto, quanto maior a descrição do objeto, melhor será o contato do setor de compras com os fabricantes, assim como uma melhor especificação dos itens auxiliará os profissionais na emissão de parecer técnico.

$\mathrm{Na}$ atualidade o comprador não pode se preocupar unicamente com a conclusão de uma compra, sem avaliar o impacto dessa operação em relação aos demais processos integrados à cadeia produtiva ou operativa das organizações (BATISTA; MALDONADO, 2008).

\subsubsection{Seção - Razão de Aprovação e Reprovação nos Pregões com Amostra}

Trata-se do número de pareceres encontrados em 40 processos com solicitação de amostras dos produtos para teste de sua eficácia conforme demonstrado no gráfico abaixo:

Gráfico 3 - Razão de aprovação e reprovação de pregões com amostras realizados em hospital universitário (Rio de Janeiro/RJ/2015).

Fonte: Elaboração própria.

O Gráfico acima representa um total de 913 pareceres, sendo no caso, 61,56 \% negativos e 
$38,44 \%$ positivos o que contribui significativamente no tempo para o término dos pregões, ou seja, quanto mais pareceres negativos no curso das licitações maior será o prazo para a homologação da compra.

Vale ressaltar a importância das análises das amostras, pois se não houvesse os testes dos produtos, estes seriam adquiridos pela instituição, já que o critério para o julgamento das propostas é o menor preço.

Contudo, há de se ressaltar que o critério menor preço jamais poderá ser sinônimo de boa qualidade, visto que as normas disciplinadoras estabelecem que a proposta deva ser a mais vantajosa para administração. Entretanto, essa "vantagem" não pode ser encarada apenas no fator menor preço, e, sim, no conjunto, pois muitas das vezes uma aparente economia imediata trará, em médio prazo, desperdícios desses materiais, já que por serem de baixa qualidade farão com que haja repetição nos procedimentos, entre outros desdobramentos em longo prazo.

Kurcgant P. e colaboradores (1991) discorrem que é com auxílio do parecer que o serviço de compras efetuará a aquisição, pois ele será utilizado como justificativa para se realizar a escolha do produto que atender às necessidades do serviço. Assim, será escolhida a proposta mais vantajosa em um conjunto que considere o preço, a qualidade e o prazo de entrega dos insumos.

Extrai-se dos argumentos, que não basta finalizar o procedimento objetivando apenas o critério menor preço, ou seja, a economia alcançada na conclusão do processo é primordial acima de tudo realizar as aquisições de bens de qualidade, haja vista que os materiais serão utilizados em pacientes debilitados, cujo objetivo é o seu bem-estar e consequente a melhora do seu quadro. Sem esquecer-se da segurança do profissional de saúde que manipula estes produtos.

Segundo Cleuza Catsue Takeda Kuwabara (2009), no momento o gerenciamento de risco se encontra em foco nas diversas realidades instituições de saúde do Brasil, por isso a implantação de modelos novos de avaliação de produtos de uso na recuperação da saúde por profissionais de formações e experiências diferentes para assim poder colaborar para uniformização de condutas com o uso do instrumento de forma mais eficaz.

Sem dúvidas, isso significa união de forças dentro dos hospitais com a colaboração de multiprofissionais na avaliação dos materiais o que ajudaria de forma salutar.

Evidenciou-se que nos trabalhos pesquisados, como no caso da obra de Simone Domingues Garcia e colaboradores (2012), a proposta de reformulação envolveria a qualidade dos materiais oferecidos, tendo em vista que por estarem atrelados ao menor preço ofertado, diminui a oportunidade do serviço de apresentar opções de escolhas em ralação a qualidade superior, por isso a melhora no descritivo dos produtos durante o processo de compras certamente contribuirá para o quesito qualidade.

O presente estudo é sem dúvida a qualidade e, por isso constata-se que há grande enfoque na responsabilidade dos profissionais de saúde na administração dos materiais hospitalares, desse modo um parecer prévio destes profissionais contribui sobremaneira na decisão da compra final.

Ventura (2010) discorre sobre a importância da relação entre qualidade e preço, tendo o enfermeiro grande importância neste processo, já que o bom desempenho do material influi na 
qualidade e segurança do serviço prestado, não somente para a enfermagem, mas para toda a instituição, sobretudo, que as decisões sobre qualidade devem estar sempre presentes em todos os planos de compra.

Destaca-se que material de baixa qualidade pressupõe desperdícios, principalmente no Centro Cirúrgico de qualquer instituição visto que é um dos setores onde são concentrados procedimentos de altíssima relevância neste sentido, destaca-se excelente trabalho de Giseli Terezinha Pagliarini Cypriano et al. (2008, p. 78):

A redução de custos e a otimização da assistência de enfermagem ao se evitar, principalmente, desperdícios de material, tempo e recursos nos setores de Centro Cirúrgico, dependem do trabalho colaborativo entre as equipes de saúde, da identificação dos resultados esperados e do uso de princípios e da melhora contínua da qualidade assistencial. É essencial a orientação do cuidado de enfermagem para o alcance de bons resultados, face às intervenções propostas e a prática assistencial baseada em evidências.

É exatamente o que se busca com a análise e emissão de pareceres baseados em evidências com objetividade nos resultados para que não haja "tendencionismos" deixando de lado a segurança dos pacientes e dos demais profissionais de saúde que prestam o atendimento ao público. Por isso, a padronização dos insumos para saúde é fundamental para dar maior eficiência e segurança a todos os envolvidos.

Dessa forma, a solução mais adequada para selecionar materiais de qualidade em hospital universitário é a constituição de comissão de pré-qualificação dos insumos adquiridos por pregão, que apesar de não haver tal previsão na Lei 10.520/02 e Decreto 5.450/05, a matéria é tratada em legislações espaças como as Leis $n^{\circ} 12.462 / 11$ e $n^{\circ} 13.303 / 16$, nas quais há a referida previsão, a saber, respectivamente:

Art. 29. São procedimentos auxiliares das licitações regidas pelo disposto nesta Lei:

I - pré-qualificação permanente; [...].

Art. 63. São procedimentos auxiliares das licitações regidas por esta Lei: I - pré-qualificação permanente;

Outrossim, a Lei n. ${ }^{\circ}$ 8.666/93 apesar de não mencionar o tema, busca de certa forma qualidade nas aquisições ao estabelecer no artigo 15 que "as compras, sempre que possível, deverão atender ao princípio da padronização, que imponha compatibilidade de especificações técnicas e de desempenho".

E, ainda o escopo do artigo $7^{\circ}, \S 5^{\circ}$ da referida legislação, possibilita a indicação de marcas, desde que tecnicamente justificável, além de previsto e discriminado no ato convocatório.

Vale ressaltar que, à comissão de padronização, ou seja, a pré-qualificação de produtos médicos hospitalares é recomendada sua instituição no parecer da Advocacia Geral da União - 
Consultoria Geral da União/ Núcleo de Assessoramento Jurídico no Rio de Janeiro/RJ:

Parecer: JLRGR/RGP/NAJ/CGU/ AGU No 12G3/2006. Referência: Processo no 25410.1884/05-31 Assunto/Ementa: Análise jurídica de Projeto de Implantação de Sistema Homologação Marcas e Produtos Médico/Hospitalares e outros. Parecer com ressalvas. Interessado: Instituto Nacional do Câncer - Ministério da Saúde [...]. De todo o exposto, resguardados o juízo de conveniência e oportunidade ínsito à esfera administrativa, dado que este parecer tem caráter apenas consultivo servindo ao administrador como base para tomada de decisão, opina-se no sentido da possibilidade de instituir-se o processo de pré-qualificação, adstrito apenas aos materiais de uso médico-hospitalar, uma vez atendidos os requisitos mínimos descritos no item VII (ANVISA, 2010, p. 47).

Pelo entendimento, verificamos que para os materiais de uso médico, em vista da sua importância na recuperação dos usuários e proteção aos profissionais que manipulam esses insumos, o melhor procedimento a ser adotado é a seleção da melhor qualidade. Comprar materiais médicos sem uma prévia avaliação pode resultar em eventos danosos; por isso, é de suma importância essa análise.

Em orientação jurídica extraída do portal Negócios Pública (2015), verificou-se que apesar da vedação mencionada na legislação de indicar marcas dos produtos a serem licitados, há uma ressalva, desde que tecnicamente justificável, bem como processo prévio de padronização:

Assunto: Licitação. Indicação de marca. Hipótese admitida. Legislação: Lei 8666/93. Lei 10520/02. Ementa: Licitação. Edital. Indicação de marca pela Administração. Regra: Impossibilidade. Hipótese admitida: 1) Mediante justificativa técnica; 2) Mediante processo prévio de padronização; 3) Como marca referencial. Considerações gerais. Necessidade de consulta a profissionais da área médico-dermatológica e/ou Sociedade Brasileira de Dermatologia (NEGÓCIOS PÚBLICOS, 2015, p. 1).

Evidentemente, não é qualquer justificativa, uma vez que tal decisão necessita ser muito bem fundamentada com o auxílio da área médica e da enfermagem, com atenção a critérios, objetivos e experiência vivenciada no uso dos insumos, para se ter conhecimento prévio para a elaboração do parecer consubstanciado.

Há de se destacar, sobretudo, que o TCU já se manifestou por diversas vezes sobre o assunto:

Sumário: Denúncia. Denominação de marca. Procedência parcial. Arquivamento. A indicação de marca na especificação de produtos de informática pode ser aceita frente ao princípio da padronização previsto no art. 15, inciso I, da Lei $\mathrm{n}^{\mathrm{o}} 8.666 / 1993$, desde que a decisão administrativa que venha a identificar o produto pela sua marca seja circunstanciadamente motivada e demonstre ser essa a opção, em termos técnicos e econômicos, mais vantajosa para a administração. (BRASIL, 2008). 
Logo, para analisar os insumos terápeuticos anteriormente às compras, ou seja, não no decorrer dos pregões é primordial a constituição de uma comissão de pré-qualificação dos materiais adquiridos no HUGG através de parecer sério e consubstanciadas, contudo, para que isso ocorra, é necessário elaborar um regimento interno que defina as atividades da referida comissão que estará subordinada à direção do Hospiatal.

Sua composição precisa ter multiprofissionais de nível superior (médico, enfermeiro, fisioterapeita, nutricionista, psicólogo, advogado e outros) pertencentes ao quadro da universidade, com rodízio a cada 12 meses para evitar "tendencionismos" que sem dúvida poderá prejudicar a seriedade dos trabalhos.

Suas competências primordiais serão receber as amostras dos produstos, encaminhálas aos setores, supervisionar os testes, emitir parecer, arquivar os preceres em um sistema de bancos de dados eletrônico, manter o banco de dados atualizado, notificar a Anvisa a respeito dos problemas identificados nos testes (queixa técnica e/ou evento adverso), atualizar as especificações da grade de material hospitalar.

A referida comissão de Pré-qualificação/Padronização deverá ser harmônica com as demais comissões do hospital, tais como Comisão de Infecção Hospitalar, Comisão de Resíduo e, principalmente, com o Núcleo de Segurança do Paciente. Os membros destas deverão compartilhar informações e conhecimentos e, quando necessário, todos emitirão parecer para auxiliar os trabalhos.

Os fornecedores deverão ser convidados por edital público a comparecer ao hospital de segunda a sexta-feira, no horário comercial, e apresentar seus produtos à comissão, com as descrições completas e toda a documentação exigida (registro do produto na Anvisa, quando houver, certificado de boas práticas de fabricação, atestado de capacidade técnica, entre outros).

Os editais de chamamento ao público deverão ser mensais, nos quais constarão quais materiais o hospital estaria testando naquele mês. Aos fornecedores, será garantido o direito de indicar um profissional da área de saúde para acompanhar os testes, caso necessário, bem como dar treinamento/esclarecimento sobre determinados produtos de seu fornecimento às suas expensas, caso necessário.

Os produtos reprovados pela comissão só serão novamente submetidos a testes após o fornecedor corrigir os problemas identificados e notificados ao NOTIVISA. Os fornecedores poderão entregar, juntamente com suas amostras, parecer técnico emitido por outra instituição que possua comissão com a mesma finalidade. O referido parecer será analisado e, caso a comissão do HUGG julgue conveniente, poderá dispensar o teste do produto.

Somente serão classificados nos pregões eletrônicos os produtos com parecer positivo emitido pela comissão.

\section{CONCLUSÃO}

A aquisição de materiais de qualidade é extremamente complexa, sobretudo nos hospitais públicos, desse modo, novas formas de gerir devem ser adotados, buscando agregar eficiência com 
qualidade.

Para que isto ocorra um dos fatores determinantes para realização de uma boa compra é o fornecimento da especificação completa do insumo terapêutico, definição correta das unidades e quantidades a ser adquirida, para garantir que não ocorram desperdícios, sobretudo a perfeita aquisição dos bens ou serviços necessários.

É primordial a integração dos profissionais de saúde envolvidos e a permanente capacitação destes.

É preciso considerar que a redução dos custos aparente nas contratações oriundas somente pelo critério menor preço poderá acarretar desperdícios futuros e atrasos no atendimento. Outro aspecto a ser mencionado é o fato de que o paciente pode ter seu quadro clínico agravado, devido a eventos adversos, e assim permaneça maior tempo internado ou aquele que apenas buscou um pronto atendimento, ter sua condição agravada por conta de materiais de baixa qualidade, isto sem dúvida trará efeitos indesejados como o aumento do custo.

Tendo em vista que esses eventos são ocorrências indesejadas, podendo quando há planejamento serem evitados e, com isso minimizar os gastos, pois estas ocorrências podem trazer várias sequelas aos pacientes e até óbitos.

Desse modo, é primordial que ações e estudos sejam desenvolvidos para dirimir e, por que não cessar as intercorrências provenientes da manipulação de materiais médicos hospitalares de baixíssima qualidade.

Hoje uma das medidas adotadas por instituições que não possuem Comissão de préqualificação é a possibilidade de solicitação de amostras nos instrumento convocatório, todavia, torna a licitação morosa o que descaracteriza o objetivo para o qual foi instituída esta nova modalidade de licitação.

A pré-qualificação dos materiais, apesar de não está amparada na Lei que instituiu o pregão é medias que se impõe, já que pode e deve trazer segurança para os que necessitam e para aqueles que utilizam estes produtos como ferramenta de trabalho, pois sem dúvida evitaria maior permanência dos pacientes internados, reduziria os custos, o tempo na aquisição e o estresse das equipes, já que materiais com desempenho inadequado não contribuem para a melhora do quadro crítico e debilitado dos pacientes.

Outra solução para pré-qualificar os materiais, por parte dos hospitais que não possuem Comissão de Pré-Qualificação, seria realizar parceria com as Instituições que já detém, a fim de que divulguem lista dos materiais analisados e aprovados nos sites governamentais, bem como forneçam aos licitantes detentores dos produtos com pareceres positivos para comprovar nos demais órgão esta condição.

Assim, os hospitais que não possuem Comissão de Pré-Qualificação poderiam acrescentarem seus instrumentos convocatórios que os detentores dos melhores lances apresentem os respectivos pareceres técnicos a fim de comprar que o produto foi avaliado por uma comissão legalmente constituída, como exemplo, do Instituto Nacional do Câncer - Ministério da Saúde, medida que sem dúvida reduziria consequentemente os custos. Logo se conclui que as aquisições pelos 
pregões, adotando-se somente o critério de menor preço estabelecido na lei que instituiu o pregão, não assegura padrão de qualidade dos materiais hospitalares, expondo pacientes e profissionais de saúde a riscos injustificáveis do ponto de vista de segurança dos pacientes e do trabalho, bem como acarreta desperdícios ao erário. Razões suficientes para apontar a necessidade da implantação de comissão de pré-qualificação dos produtos para analisá-los antes dos procedimentos licitatórios realizados no hospital universitário no qual se realizou a pesquisa, bem como é indicativo para outras instituições públicas de saúde que não detém.

\section{REFERÊNCIAS}

ANVISA - AGÊNCIA NACIONAL DE VIGILÂNCIA SANITÁRIA. Pré-qualificação de artigos médico-hospitalares: estratégia de vigilância sanitária de prevenção. Brasília, DF: Ministério da Saúde, 2010. Disponível em: http://portal.anvisa.gov.br/wps/wcm/ connect/1776d7804745929f9b00df3fbc4c6735/Capa+-+Manual+de+Pré-+Qualificação. pdf?MOD=AJPERES. Acesso em: 12 set. 2018.

BATISTA, Marco Antonio Cavalcanti; MALDONADO, José Manuel Santos de Varge. O papel do comprador no processo de compras em instituições públicas de ciência e tecnologia em saúde (C\&T/S). Revista de Administração Pública, Rio de Janeiro, v. 42, n. 4, p. 681- 699, ago. 2008. Disponível em: http://dx.doi.org/10.1590/S0034-76122008000400003. Acesso em: 2 dez. 2015.

BRASIL. Decreto ${ }^{0} 5.450$, de 31 de maio de 2005. Regulamenta o pregão, na forma eletrônica, para aquisição de bens e serviços comuns, e dá outras providências. Brasília, DF: Presidência da República, 2005. Disponível em: http://www.planalto.gov.br/ccivil_03/_ato2004-2006/2005/ decreto/d5450.htm. Acesso em: 13 fev. 2017.

BRASIL. Lei $\mathrm{n}^{\mathrm{o}}$ 10.520, de 17 de julho de 2002. Institui, no âmbito da União, Estados, Distrito Federal e Municípios, nos termos do art. 37, inciso XXI, da Constituição Federal, modalidade de licitação denominada pregão, para aquisição de bens e serviços comuns, e dá outras providências. Brasília, DF: Presidência da República, 2002. Disponível em: http://www.planalto. gov.br/ccivil_03/Leis/2002/L10520.htm. Acesso em: 13 fev. 2017.

BRASIL. Lei $\mathrm{n}^{\circ}$ 12.462, de 04 de agosto de 2011. Institui o Regime Diferenciado de Contratações Públicas - RDC; altera a Lei no 10.683, de 28 de maio de 2003, que dispõe sobre a organização da Presidência da República e dos Ministérios, a legislação da Agência Nacional de Aviação Civil (ANAC) e a legislação da Empresa Brasileira de Infraestrutura Aeroportuária (Infraero); ... Brasília, DF: Presidência da República, 2011. Disponível em: http://www.planalto. gov.br/ccivil_03/_Ato2011-2014/2011/Lei/L12462.htm. Acesso em: 13 set. 2018.

BRASIL. Lei $\mathrm{n}^{\mathrm{o}} 13.303$ de 30 de junho de 2016. Dispõe sobre o estatuto jurídico da empresa pública, da sociedade de economia mista e de suas subsidiárias, no âmbito da União, dos Estados, do Distrito Federal e dos Municípios. Brasília, DF: Presidência da República, 2016. Disponível em: http://www.planalto.gov.br/ccivil_03/_Ato2015-2018/2016/Lei/L13303.htm. Acesso em: 13 set. 2018.

BRASIL. Lei nº 8.666, de 21 de junho de 1993. Regulamenta o art. 37, inciso XXI, da Constituição Federal, institui normas para licitações e contratos da Administração Pública e dá outras providências. Brasília, DF: Presidência da República, 1993. Disponível em: http://www. 
planalto.gov.br/ccivil_03/Leis/L8666cons.htm. Acesso em: 14 fev. 2017.

BRASIL. Tribunal de Contas da União. Processo: 022.814/2007-3. Relator: Ministro Valmir Campelo. 23 abr. 2008. Disponível em: https://contas.tcu.gov.br/juris/SvlHighLig ht?key=41434f5244414f2d434f4d504c45544f2d3336373736\&sort=RELEVANCIA\&or dem=DESC\&bases $=$ ACORDAO-COMPLETO; \&highlight $=\&$ posicaoDocumento $=0 \&$ numDocumento $=1 \&$ totalDocumentos $=1$. Acesso em: 13 set. 2018 .

COMPRASNET. Pregão eletrônico reduziu custos das compras do governo federal em até 30\% em dois anos. 2005. Disponível em: http://www.comprasnet.gov.br/noticias/noticias1.asp?id_ noticia=159. Acesso em: 16 jun. 2016.

CROOM, Simon R. The Impact of Web Based Procurement on the Management of Operating Resources Supply. Journal of Supply Chain Management, v. 36, n.4, p. 4-13, dec.2000.

CYPRIANO, Giseli Terezinha Pagliarini; UJAQUE, Ozeias; LIMA, Rogério Rodrigues de; ZBOROWSKI, Ilza dos Passos. Padronização de kits de materiais cirúrgicos: proposta para implantação. Revista Cuidarte de Enfermagem, São Paulo, v. 1, n. 1, p. 78, 2008.

DI PIETRO, Maria Sylvia Zanella. Direito administrativo. 23. ed. São Paulo: Atlas, 2010.

FARIA, Evandro Rodrigues de; FERREIRA, Marco Aurélio Marques; SANTOS, Lucas Maia dos; SILVEIRA, Suely de Fátima Ramos. Pregão Eletrônico Versus Pregão Presencial: Estudo Comparativo de Redução de Preços e Tempo. Revista de Contabilidade do Mestrado em Ciências Contábeis da UERJ, Rio de Janeiro: v. 16, n. 1, p.47-62, jan./abr. 2011. Disponível em: http:// www.e-publicacoes.uerj.br/index.php/rcmccuerj/article/view/5478. Acesso em: 14 fev. 2017.

FARIA, Evandro. Rodrigues de; FERREIRA, Marco Aurélio Marques; SANTOS, Lucas Maia dos; SILVEIRA, Suely de Fátima Ramos. Estudo Comparativo de Redução de Custos e Tempo nas Modalidades de Licitação por Pregão Eletrônico e Presencial. In: CONGRESSO USP CONTROLADORIA E CONTABILIDADE, 8., 2008, São Paulo. Anais [...]. São Paulo: USP, 2008. p. 1-13.

FREITAS, Manuel; MALDONADO, José Manuel Santos de Varge. O pregão eletrônico e as contratações de serviços contínuos. Revista de Administração Pública: Rio de Janeiro, v. 47, n. 5, p. 1265-1281. set./out. 2013. Disponível em: http://bibliotecadigital.fgv.br/ojs/index.php/rap/ article/view/12052/10971. Acesso em: 13 mar. 2016.

GARCIA, Simone Domingues; HADDAD, Maria do Carmo Lourenço; DELLAROZA, Mara Solange Gomes; COSTA, Daniele Bernardi da; MIRANDA, Juranda Maia de. Gestão de material médico-hospitalar e o processo de trabalho em um hospital público. Revista Brasileira de Enfermagem, Brasília, DF, v. 65, n. 2, p. 339-346, abr. 2012.

JUSTEN FILHO, Marçal. Comentários à legislação do pregão comum e eletrônico. 5. ed. São Paulo: Dialética, 2009.

KURCGANT, Paulina. Administração em enfermagem. São Paulo: EPU, 1991.

KUWABARA, Cleuza Catsue Takeda. Gerenciamento de risco em tecnovigilância: aplicação dos conceitos seis sigma e técnica delphi para o desenvolvimento e validação de instrumento de avaliação de material médico-hospitalar. Tese (Doutorado em Enfermagem Fundamental) 
- Escola de Enfermagem de Ribeirão Preto, Universidade de São Paulo. Ribeirão Preto, 2009. Disponível em: http://www.teses.usp.br/teses/disponiveis/22/22132/tde-07102009-145936/pt-br. php. Acesso em: 13 mar. 2016.

NEGÓCIOS PÚBLICOS. Licitação: Indicação de Marca: Hipóteses admitidas. 2015. Disponível em: http://www.negociospublicos.com.br/. Acesso em: 13 set. 2018.

VENTURA, Palloma Fernandes Estanislau Vaz. Participação do enfermeiro na gestão de recursos hospitalares. Dissertação (Mestrado em Enfermagem) - Universidade Federal de Minas Gerais, Belo Horizonte, 2010. Disponível em: http://www.bibliotecadigital.ufmg.br/dspace/ handle/1843/GCPA-8GSJKX. Acesso em: 13 mar. 2016.

Como citar: VILAS FILHO, Fabio Gonçalves; MACHADO, Wiliam Cesar Alves; FIGUEIREDO, Nébia Maria Almeida. Visão jurídico-administrativa nas aquisições por pregão: busca de qualidade em hospital universitário do rio de janeiro. Revista do Direito Público, Londrina, v. 14, n. 2, p. 1027, ago. 2019. DOI: 10.5433/24157-108104-1.2019v14n2p. 10. ISSN: 1980-511X

Recebido em: 24/09/2017.

Aprovado em: 28/01/2019. 